\title{
Proteção social no olho do furacão: contrarreformas na América Latina
}

\author{
Social protection in the eye of hurricane: counter-reforms in Latin America
}

Rodrigo Cristiano DIEHL*

http://orcid.org/oooo-0002-4869-3112

Jussara Maria Rosa MENDES**

https://orcid.org/oooo-0002-3908-4964

\begin{abstract}
Resumo: O presente estudo tem por objetivo compreender os principais elementos (políticos, econômicos e sociais) presentes nos processos de reforma e/ou contrarreforma dos sistemas de proteção social na América Latina. O caminho metodológico foi oportunizado pela pesquisa bibliográfica de natureza exploratória-descritiva e de caráter quantitativo e qualitativo e também pelo materialismodialético enquanto método e percurso da produção do conhecimento. De tal modo, o estudo parte do seguinte questionamento: quais são os principais elementos presentes nos processos de reforma e/ou contrarreforma nos sistemas de proteção social na América Latina? Entre as principais conclusões, destaca-se a semelhança nas contrarreformas estruturais no que diz respeito à necessidade de atender às novas exigências do capital, com o apoio de agências multilaterais na diminuição dos gastos sociais para possibilitar novas condições para a livre circulação do capital e o aumento de seus lucros.
\end{abstract}

Palavras-chave: América Latina. Contrarreforma. Proteção social.

Abstract: This study aims to understand the main elements (political, economic, and social) present in the reform and counter-reform processes of social protection systems in Latin America. The methodology was exploratory-descriptive, quantitative, and qualitative bibliographic research and using dialectical materialism as a method and pathway for knowledge production. The study starts from the following question: what are the main elements present in the reform and counter-reform processes in social protection systems in Latin America? Among the main conclusions, we highlight the similarity in structural counter-reforms regarding the need to meet the new capital requirements, which requires the support of multilateral agencies and reduced social spending to enable new conditions for the free movement of capital and increased profits.

Keywords: Latin America. Counter-reform. Social protection.

Submetido em: 6/1/2020. Revisado em: 25/4; 12/6; 5/7/2020. Aceito em: 6/7/2020.

\begin{abstract}
* Advogado e Professor. Mestre em Direito e Política Social. Doutorando em Direito pelo Programa de Pós-Graduação em Direito da UNISC com coorientação pelo Programa de Pós-Graduação em Ciência Política da UFRGS. Universidade de Santa Cruz do Sul, (UNISC, Santa Cruz do Sul, Brasil). Av. Independência, 2293, Santa Cruz do Sul (RS), Cep 96815-900. Bolsista CAPES. E-mail: rodrigocristianodiehl@gmail.com.

** Assistente Social. Doutora em Serviço Social pela PUC/SP. Pós-doutorado em Serviço Social. Professora colaboradora do Programa de Pós-Graduação em Política Social e Serviço Social e do Programa de Pós-Graduação em Psicologia Social e Institucional, ambos da Universidade Federal do Rio Grande do Sul. (UFRGS, Porto Alegre, Brasil). Av Paulo Gama, 110, Bairro Farrukhabad, Porto Alegre (RG), CEP.: 90040-060. Representante de área junto ao CNPq. E-mail: jussaramaria.mendes@gmail.com.
\end{abstract} copiar e redistribuir o material em qualquer suporte ou formato, bem como adaptar, transformar e criar a partir deste material para qualquer fim, mesmo que comercial. O licenciante não pode revogar estes direitos desde que você respeite os termos da licença. 


\title{
1 Considerações iniciais
}

\begin{abstract}
A o desembarcar no novo continente, o neoliberalismo encontrou um ambiente propício à propagação de suas ideias em grande escala: Estados destruídos economicamente, regimes democráticos em fase embrionária após duros anos de ditaduras (civis/militares), sociedades altamente estratificadas com mares de pobreza e ilhotas de riqueza concentrada e, com isso, pessoas à mercê de qualquer auxílio estatal. Contraditoriamente com esse cenário de filme de terror, porém real, havia uma semente sendo gestada: a possibilidade de reconstruir as nações e erguer/consolidar um espírito latino-americano de desenvolvimento.
\end{abstract}

De tal modo, a análise de sociedades que detêm como marca central amplas desigualdades sociais, econômicas e políticas e o não acesso por grande parte da população aos sistemas de proteção social por meio da garantia dos direitos sociais, como é o caso das latino-americanas, deve pautar o estudo sobre o papel do Estado ao demonstrar a extrema importância de configurar-se, ou pelo menos teoricamente, como agente responsável por concretizar direitos e afastar a dominação por parte do capital periférico dos principais espaços de poder e decisão.

Em virtude de representar uma das maiores e principais fontes de provisão de bem-estar das sociedades, os sistemas de proteção social são compreendidos, neste trabalho, como elementos situados no olho do furacão, termo que se refere, popularmente, a um ambiente problemático e perigoso, mas que para a ciência que estuda os fenômenos naturais é um local de extrema calmaria. Essa contradição pode ser visualizada nas alterações promovidas nos sistemas de proteção social, ao se constituir como alvo de políticas neoliberais e neoconservadoras já conhecidas e transvestidas que promovem o seu desmonte e a sua descaracterização, implicando de forma direta a não concretização de direitos.

Diante desse contexto, o presente estudo tem por objetivo compreender os principais elementos (políticos, econômicos e sociais) presentes nos processos de reforma e/ou contrarreforma dos sistemas de proteção social na América Latina. Importante mencionar que, ao dialogar com sistemas de proteção social, Estado, capitalismo periférico e neoliberalismo na América Latina, não se deve esquecer das inúmeras especificidades de cada Estado (muitas vezes, uma multiplicidade de construções inclusive no âmbito interno), logo, o que neste estudo se faz é buscar reunir elementos próximos que permitam traçar vínculos (semelhanças e diferenças).

Na construção do trabalho, o percurso metodológico utilizado em relação aos objetivos segue uma investigação exploratória-descritiva. Referentemente aos procedimentos, realiza-se uma investigação bibliográfica quantitativa e qualitativa (com foco na produção qualificada em periódicos classificados no estrato A no sistema brasileiro Qualis/CAPES). Por sua vez, para a análise dos dados é utilizado o método materialismodialético por permitir aproximações dos fenômenos naturais e sociais a partir do ponto dialético, o que possibilita sua interpretação, sua maneira de focalizá-los, na perspectiva de materializar um movimento real, suas contradições e forças.

Argum., Vitória, v. 12, n. 2, p. 284-298, maio/ago. 2020. | ISSN 2176-9575 
O processo de coleta de dados foi pautado pela adoção de alguns critérios que serviram para delimitar o universo de estudo e orientar a seleção do material. Foram critérios de inclusão e exclusão da pesquisa:

a) seleção dos periódicos classificados no sistema Qualis/CAPES, avaliação quadrienal 2013/2016 na área de avaliação do Serviço Social;

b) exclusão dos periódicos não classificados no estrato A (A1 e A2);

c) exclusão de periódicos semelhantes (numeração de registro diversa para versão impressa e on-line);

d) exclusão dos periódicos não originários da América Latina;

e) exclusão dos periódicos que não estavam vinculados diretamente à área do Serviço Social ou ao Programa de Pós-Graduação em Serviço Social (e variações dentro da área de avaliação da Coordenação de Aperfeiçoamento de Pessoal de Nível Superior).

Para realizar a coleta em cada periódico selecionado anteriormente, foram definidos quatro descritores, sendo eles: América Latina (localização geográfica do estudo), Estado (estrutura inserida no capitalismo periférico), proteção social (núcleo rígido de garantia de direitos) e, por fim, reforma e/ou contrarreforma (procedimentos utilizados para estruturar e desmontar os sistemas de proteção social). Vale ressaltar que, nos descritores, foram utilizados tanto o termo reforma quanto o termo contrarreforma para a seleção do material.

O problema de pesquisa que orienta a discussão é: quais são os principais elementos semelhantes (políticos, econômicos e sociais) presentes nos processos de reforma e/ou contrarreforma nos sistemas de proteção social na América Latina?

\section{Reformas e contrarreformas nos sistemas de proteção social na América Latina}

As reatualizações na lei geral de acumulação capitalista, vinculadas ao ideário neoliberal, ocasionaram impactos sociais e políticos na intervenção do Estado nas expressões da questão social, ao construírem, contraditoriamente, um Estado forte e enxuto. Essa construção caminha na contramão das conquistas dos trabalhadores por garantia de direitos sociais por meio da estruturação de sistemas de proteção social capazes de diversificar aspectos da vida social, observados, por exemplo, na cooptação de movimentos sociais, na redefinição de práticas e na inflexibilidade de partidos políticos (VALLE, 2013).

Nesse ambiente, a subsunção da cidadania atrelada à proteção social, às desigualdades de classes e às opressões de raça e gênero nas sociedades latino-americanas reflete em uma visão que não coaduna com o significado de ser protegido. A proteção desejada, de acordo com Pereira (2016), pressupõe uma distribuição da riqueza socialmente produzida, mesmo dentro de uma sociedade marcada pela competitividade e pela meritocracia, em um ambiente onde são preservadas e valorizadas a estratificação social, a concentração de renda, a acumulação de capital sem controle e o consumo não consciente.

Argum., Vitória, v. 12, n. 2, p. 284-298, maio/ago. 2020. | ISSN 2176-9575 
Na América Latina ${ }^{1}$, o desenvolvimento de Estados sociais teve limites precisos: junto com os processos que possibilitaram a ampliação da cidadania atrelada ao mundo do trabalho, conviviam grandes setores das sociedades que não lograram êxito em se integrar aos sistemas de proteção social. Tais setores não estavam vinculados ao trabalho, sendo que operavam como exército industrial de reserva (BENTURA, 2014).

Esse contexto de contradições tem influência na construção da questão social porquanto, desde meados do século XIX, aumentavam-se as críticas e as pressões contra o pauperismo das massas e o assistencialismo. A partir disso, reformadores passaram a denominar esse movimento de questão social, objetivando a introdução de medidas de proteção social ao arrepio dos princípios liberais vigentes (PEREIRA, 2009).

Nas mediações que o Estado se vê compelido, pela ação de classes e frações de classes, a introduzir no trato sistemático das refrações da 'questão social', o Serviço Social pode desincumbir-se das suas tarefas contemplando diferencialmente os vários protagonistas socio-históricos em presença. A opção por um tratamento privilegiado de qualquer um deles, porém, não é função de uma escolha pessoal dos profissionais - ainda que a suponha, é variável da ponderação social e da força polarizada dos protagonistas (NETTO, 1992, p. 76).

Um dos pilares de sustentação dessa tendência foi a desmistificação das causas da pobreza, tendo por base os estudos realizados em 1886 por Charles Booth e Seebohm Rowntree. A questão social, afastando a compreensão dos sistemas de proteção social residuais ou meritocráticos, não pode ser envolvida como sinônimo de problema social ou de uma pobreza que seja remetida ao indivíduo, isolado ou socialmente construído, para que ele seja o responsável pelo conjunto de carências e/ou privações por ela produzidas (RAICHELIS, 2006). Pelo contrário, deve ser vista como o resultado de um processo histórico de lutas na relação entre capital e trabalho, não como algo estático, isolado ou simplesmente como um problema natural das sociedades.

Um dos desafios com o cenário apresentado é construir a articulação entre a questão social e a política de proteção social, especialmente no que diz respeito à assistência social, à saúde, à educação e à previdência social, para que juntas possam compreender o contexto sociopolítico de vulnerabilidades e promover alterações/adequações. Todavia, compreendendo a efetivação da proteção social na América Latina em tempos de contrarreforma, em especial no caso brasileiro, é possível traçar alguns pontos comuns que impactam, de maneira negativa, os sistemas de proteção social, sendo eles: forte diminuição no investimento social por parte dos governos centrais, desarticulação das redes de serviços sociais, promovendo a volta do estilo clientelista e patrimonialista de administração da política social, e (re)filantropização da política social (SENNA; MONNERAT, 2010).

A tendência percebida em grande parte dos Estados latino-americanos acaba promovendo a redução de direitos, garantias e limitações das possibilidades preventivas e redistributivas das políticas sociais. Consequentemente, implementa-se, de modo mais

\footnotetext{
${ }^{1}$ Importante ressaltar que Cuba, diante de sua experiência de transição socialista, estabeleceu uma noção própria de desenvolvimento e de fundamentos que articulam seus sistemas de proteção social, que se diferenciam dos aspectos tratados neste trabalho em relação aos demais países capitalistas latinoamericanos.
} 
feroz, o trinômio do neoliberalismo: privatização dos serviços públicos, focalização das demandas e descentralização (sendo o último aspecto atrelado à desconcentração e à desresponsabilização).

Na relação entre o capitalismo contemporâneo e os sistemas de proteção social, desde o Consenso de Washington (1989), as diretrizes do Banco Mundial e do Fundo Monetário Internacional estão direcionadas para contrarreformas que objetivem a diminuição ou o afastamento do Estado da concretização de direitos sociais. Com isso, de acordo com Marques e Mendes (2013), houve uma série de flexibilizações no mundo do trabalho como: redução do custo da força de trabalho com a respectiva precarização das relações laborais, substituição dos sistemas públicos por sistemas privados ou de capitalização, entre muitas outras.

Essas diretrizes de contrarreformas e de capitalização impostas pelo capital podem ser visualizadas ainda hoje e, talvez com maior intensidade, nos sistemas de proteção social que, até então, foram inicialmente estruturados na lógica do Welfare State, isto é, da atuação do Estado na garantia e no financiamento da proteção do trabalhador e da sociedade. Em decorrência desse processo, tinha-se a proteção social enquanto um direito de cidadania (de todos), e não como um direito contributivo (para apenas uma parcela da sociedade) (SILVA; SCHMIDT, 2016).

A adoção do termo contrarreforma torna-se evidente, segundo Behring (2008):

[...] se considerando a história do século XX em nível mundial, na qual o que se pode chamar de reforma associava-se ao Welfare State - uma reforma dentro do capitalismo, sob a pressão dos trabalhadores, com uma ampliação sem precedentes do papel do fundo público, desencadeando medidas de sustentação da acumulação, ao lado da proteção ao emprego e demandas dos trabalhadores, viabilizada por meio dos procedimentos democráticos do Estado de direito, sob a condução da socialdemocracia (BEHRING, 2008, p. 129).

Durante o século XX, os elementos formadores do cenário social, político e econômico possibilitaram uma reforma, isto é, uma tentativa temporal e geopoliticamente localizada entre a acumulação e a diminuição dos níveis de desigualdade por meio da redistribuição. Contudo, na era do neoliberalismo global, as reformas propostas apresentam-se como uma reação conservadora e monetarista das classes dominantes que detêm uma clara natureza regressiva, dentro da qual se situa a contrarreforma do Estado e dos sistemas de proteção social (BEHRING, 2008).

Nesse ponto, é importante relembrar que a implementação das diretrizes e políticas do neoliberalismo iniciou a partir dos anos 1990 na América Latina, sobretudo pelo Consenso de Washington, com as denominadas reformas estruturais, ou ajustes estruturais, com o objetivo de realizar mudanças nas políticas econômicas, sociais e fiscais dos países periféricos para superar os desequilíbrios econômicos causados pela crise do capital internacional desde os anos de 1970 (SANTOS, 2017). Junto a essas reformas estruturais, estavam mudanças na gestão e na estruturação de políticas sociais dos sistemas de proteção social.

Argum., Vitória, v. 12, n. 2, p. 284-298, maio/ago. 2020. | ISSN 2176-9575 
Portanto, as comumente chamadas reformas orientadas pelo neoliberalismo são, na verdade, contrarreformas, uma vez que estão direcionadas a proteger e a ampliar o mercado. Behring e Boschetti (2011) asseguram que as sociedades contemporâneas, inclusive as latino-americanas, desenvolveram suas políticas sociais sob forte espírito reformista, mas que, adentraram em um ambiente contrarreformista "[...] em tempos de estagnação, reação burguesa e neoliberalismo” (BEHRING; BOSCHETTI, 2011, p. 148).

Tendo por base elementos críticos, é possível concluir que, atualmente, o que ocorre nos Estado latino-americanos são contrarreformas de Estado, na exata definição de um conjunto de alterações que restringe o acesso a direitos, inclusive alterando marcos legais (seja em textos constitucionais ou infraconstitucionais). Nesse cenário de contrarreformas é possível verificar também outro processo que funciona como um silenciador, de acordo com Amaral (2018): a indução de uma nova cultura do trabalho que afasta o trabalho protegido e coletivo para o surgimento daquele com traços individualizantes, tais como empreendedorismo, flexi-segurança, autoemprego.

Sob o argumento de crise e da necessidade de superá-la, essas medidas implementadas na Europa e agora com maior robustez na periferia do sistema capitalista, na América Latina, possibilitam diversas formas de ocupações flexíveis que combinam várias configurações de regime: tempo de trabalho (tempo parcial e tempo intermitente), contratos de trabalho (terceirização e subcontratação), organização da produção (descentralizada, home office) e condições de trabalho (salário, qualificação, produção e proteção contra acidentes) (AMARAL, 2018).

O baixo crescimento econômico, a queda na arrecadação pública, o desemprego em alta e o desequilíbrio das contas públicas formam a receita perfeita para a construção da crise do Estado (e não crise do capital). Contudo, Lourenço, Lacaz e Goulart (2017) sinalizam para a importância de compreender esse fenômeno não como algo isolado, existente em um único país ou região do globo, mas como uma requisição do capitalismo globalizado, que necessita ampliar as taxas de acumulação para se manter ativo.

Os direitos sociais operacionalizados e concretizados pelos sistemas de proteção social também são concebidos como advindos do trabalho. Por um lado, têm-se aqueles direitos vinculados ao trabalho formal e remunerado, como, por exemplo, programas que objetivam a inserção das mulheres no mercado de trabalho; por outro lado, têm-se os direitos sociais desvinculados da relação de trabalho formal, que apresentam como características a precariedade, a discricionariedade e a condicionalidade (CARLOTO; NOGUEIRA, 2018).

As soluções propostas para a crise global, vinculadas à reestruturação do capital, ocasionam uma ofensiva sobre todos esses direitos e estão estruturadas, segundo Santos (2017), em três pilares: a reestruturação produtiva, a financeirização do capital e a política neoliberal. O primeiro pilar visa a realização de um conjunto de alterações na produção, em especial na flexibilização da contratação da força de trabalho e na garantia de direitos. O segundo pilar é verificado na intensificação da especulação financeira como forma de desenvolvimento de um capital fictício. Por fim, o terceiro pilar da estruturação do capital está fundado na política neoliberal, que guarda uma relação 
estreita entre a atuação econômica e política de Estado, sobretudo no atendimento à área social. Nesse momento, incentivos públicos às empresas privadas, privatizações de empresas públicas e políticas econômicas e sociais pensadas por agências multilaterais (como o Fundo Monetário Internacional e o Banco Mundial) são alguns dos elementos presentes no desmonte dos sistemas de proteção social (SANTOS, 2017).

Todas essas modificações devem ser analisadas no contexto político, social e econômico da América Latina. Destaca-se, portanto, segundo dados do Anuário Estatístico da América Latina e Caribe construído pela Comissão Econômica para a América Latina e o Caribe (2019), que os gastos públicos na maioria dos países latino-americanos não chegam a $15 \%$ do Produto Interno Bruto (PIB), sendo que Argentina, Brasil e Uruguai alcançaram um pouco mais de $20 \%$ e que apenas em Cuba o gasto chegou a $40 \%$ do PIB em 2010. Outros dados relevantes na análise são aqueles vinculados à taxa de pobreza e à indigência, que na população latino-americana são de $28,2 \%$ e $11,3 \%$, respectivamente.

Mesmo diante desse cenário social preocupante, as políticas sociais na América Latina encontram-se inseridas em uma dinâmica estrutural de dependência, periférica e de superexploração do capital. Esses elementos em conjunto se articulam para a não garantia de um nível básico de proteção social, para que seja possibilitado dispor do fundo público para o pagamento de dívida tornada pública (SOUZA, 2016). Mesmo que o desmonte dos sistemas de proteção social possa ser próximo na Europa e na América Latina, nesta última há ainda a presença da subordinação ao imperialismo e ao domínio dos interesses burgueses nacionais que afastaram (e continuam afastando) toda e qualquer possibilidade objetiva de um sistema de políticas sociais plenamente desenvolvidas.

Diferentemente do que ocorreu com os países de capitalismo central, nos quais a política comercial é caracterizada pelo protecionismo, aqueles países latino-americanos, como o Brasil e a Argentina, que buscaram auxílio financeiro nas agências multilaterais para equilibrar as contas públicas ficaram à mercê de suas imposições contrarreformistas e tiveram, inclusive, que desregular seus mercados, privatizar o setor público e os serviços públicos e reduzir a atuação do Estado na área social. Todas essas imposições ocasionaram relevantes prejuízos aos sistemas de proteção social em detrimento do equilíbrio da balança de pagamentos da dívida externa.

Um elemento central nos processos de contrarreforma e na manutenção da subordinação dos países periféricos ao centrais é a dívida pública que, de acordo com Silva (2018), é indispensável na reprodução da sociedade burguesa, acirrando a crise no sistema produtivo e refletindo negativamente no financiamento dos direitos sociais. A ideia de défice das contas públicas, incluindo aqui o denominado défice da previdência, é ardilosa e se apresenta como uma estratégia do bloco hegemônico em favorecer os interesses do capital. Desse modo, a dívida externa, controlada pelas classes dominantes, ocasiona a fragilização das políticas sociais na América Latina, e o projeto neoliberal em execução possibilita a subordinação dos Estados periféricos ao cumprimento do regramento dos organismos multilaterais (SILVA; SCHMIDT, 2016).

Argum., Vitória, v. 12, n. 2, p. 284-298, maio/ago. 2020. | ISSN 2176-9575 
Deve-se pensar nas repercussões dessa fragilização dos sistemas de proteção social em um mundo onde apenas $1 \%$ da população mundial detém a mesma riqueza que os outros $99 \%$ ou, também, onde oito pessoas possuem o mesmo que a metade mais pobre da população. Esses dados da Oxfam Brasil (2018) revelam, dentro da lógica capitalista neoliberal, o crescimento exponencial da riqueza entre as classes dominantes e o aumento, também exponencial, das desigualdades.

Contraditoriamente, como forma de manter os atuais níveis de acumulação e exploração do capital e de garantir o básico de existência para a população mais pobre, os países da América Latina intentam combater à pobreza por meio de políticas sociais, agrupandoas em quatro grupos: políticas e programas de transferências sociais (transferência de renda, condicionadas ou não), programas assistenciais emergenciais (ações sociais de emergência, como a distribuição de cestas básicas de alimentos), políticas estruturais de combate à pobreza (incentivo ao emprego, fortalecimento de organizações comunitárias) e políticas destinadas aos grupos sociais específicos (combate à pobreza em grupos de mulheres, crianças, pessoas com deficiência e em grupos étnicos específicos) (MATTEI, 2013).

Diante desse cenário de atuação dos Estados por meio de políticas sociais, a crise nos Estados na América Latina é atribuída, conforme Bentura (2014), em grande parte pela crítica neoliberal e neoconservadora à incapacidade de incorporar esses setores. Argumenta-se que a grande dívida dos Estados tem sido sua incapacidade de combater a pobreza e, como resposta, se propõem as novas políticas sociais que tendencialmente aumentam a desproteção dos setores integrados, o que vai de encontro à necessidade de focalizar os sistemas de proteção social nos setores marginalizados.

Para Boschetti (2009), o desmonte (ou descaracterização) dos sistemas de proteção social pode ser concebido a partir de três caminhos: a desconfiguração dos direitos previstos nas constituições, uma vez que grande parte deles ainda não foi universalizado; o caminho do desmonte que perpassa a fragilização dos espaços de participação e de controle democrático; e o orçamento, com isenções e desvios legais (do ponto de vista jurídico-positivo) de recursos que deveriam ser destinados integralmente à proteção dos indivíduos.

Nesse processo, as contrarreformas em curso na América Latina visam atacar os pilares dos princípios universais dos sistemas de proteção social. Para possibilitar esse ataque, há também em curso um processo político e ideológico para limitar a atuação do Estado na seara social, para que seja possível a exploração das políticas sociais pelo capital. $\mathrm{O}$ início desse processo, segundo Lourenço, Lacaz e Goulart (2017), ocorreu em 1989 com o Consenso de Washington e com a ligação direta dos direitos de cidadania com a necessidade de consumo.

Contudo, Marques e Mendes (2013) trazem uma ressalva dentro dos processos de contrarreforma: é importante pontuar que não houve até o momento uma completa destruição dos sistemas de proteção social pensados, organizados e garantidos pelo Estado. O que está ocorrendo constantemente com o avançar do neoliberalismo é uma destruição (ou privatização dos sistemas públicos) no mundo. Durante os anos de 1990 e 2000, por exemplo, as maiores mudanças ocorreram em solo latino-americano, embora

Argum., Vitória, v. 12, n. 2, p. 284-298, maio/ago. 2020. | ISSN 2176-9575 
as condições de acesso e de cobertura tenham piorado em outras regiões do mundo, como na Europa.

Devido a esse fato, na etapa atual do processo de desmonte é essencial verificar a intersecção entre o econômico e o político, ambiente no qual avança o conservadorismo, especialmente para acirrar o campo econômico (COUTO; RIZZOTTI, 2016). Esse contexto dificulta o pensar e o desenvolver de novos pactos civilizatórios que levariam as sociedades latino-americanas à recuperação da verdadeira natureza humana, na qual o trabalho se certifica pela capacidade criadora e pelo reconhecimento dos sujeitos em seu caminho histórico.

Sob a égide neoliberal e neoconservadora, Pereira (2016) explica que a proteção social sofreu uma forte reorientação tanto em sua fundamentação quanto em sua aplicação, sendo agora pautada por novos e contraditórios referenciais teóricos e ideológicos, que estão a serviço da necessidade urgente de respostas econômicas e políticas à crise da superprodução capitalista. Para o autor, as respostas dadas pelo sistema estatal para auxiliar o capitalismo a perpetuar-se podem ser divididas em dois principais pilares:

a) a reorganização do sistema de trabalho, promovendo a substituição do sistema fordista (no qual cada trabalhador é especializado em apenas uma atividade específica) para o sistema toyotista ou pós-fordista (no qual os trabalhadores são treinados para conhecer todo o processo de produção e não apenas uma tarefa específica), objetivando o aumento da produtividade por meio da intensificação do trabalho, eliminando os tempos mortos, ou como Marx os denominou, os "poros mortos";

b) a adoção de uma nova base tecnológica fundada na eletrônica, na informática e na telemática, o que para muitos resultou na terceira revolução industrial.

A propositura dessas alterações encontra-se, no caso brasileiro, em contradição com a reforma democrática promovida pela Constituição Federal de 1988 ao estabelecer o capítulo da ordem social influenciada por princípios da socialdemocracia e do welfarismo. De acordo com Behring e Boschetti (2011), essa contrarreforma em curso da atuação do Estado na proteção social provoca o solapamento da possibilidade política, mesmo que limitada, de promoção "[...] de reformas mais profundas no país, que muito possivelmente poderiam ultrapassar os próprios limites da socialdemocracia, realizando tarefas democrático-burguesas inacabadas em combinação com outras de natureza socialista" (BEHRING; BOSCHETTI, 2011, p. 150).

Deve-se reconhecer o Estado e a sociedade como espaços contraditórios, especialmente diante das usurpações de direitos que afetam diretamente as condições de vida do trabalhador e de sua família. Nesse sentido, “[...] nem o Estado nem o governo que está no poder e nem a sociedade ou as instituições que a conformam são blocos monolíticos e homogêneos; esses são constituídos por forças sociais em confronto" (BEHRING; BOSCHETTI, 2011, p. 198). Explorar as contradições deve se tornar um movimento constante de luta contra-hegemônica, por reconhecer-se que a totalidade é formada por elos indissociáveis. 
No desenvolver dos processos de contrarreformas na América Latina, outro fator importante de análise é a convocação das famílias para que supram os défices do Estado na proteção social, movimento que Carloto e Nogueira (2018) denominam de neoliberalismo familista. Diferentemente da ideia difundida em algumas fases do capitalismo periférico de que as famílias são responsáveis pela proteção social, com o neoliberalismo ocorreu um novo delineamento dessa relação: a atuação deve ocorrer devido à drástica diminuição de investimentos públicos em políticas sociais, ocasionando inclusive a feminização da pobreza, uma vez que reproduz o ciclo intergeracional e reafirma os papéis de gênero tradicionais.

Sabe-se que lutas e mudanças não terão efeitos imediatos, mas que atitudes cotidianas e mediatas têm e terão implicações na totalidade. Isso pode ser observado no caso brasileiro, no qual é possível perceber de maneira clara a luta entre dois projetos de sociedade: de um lado, há classes dominantes querendo afirmar seu poder hegemônico e implantar de vez o modelo neoliberal e neoconservador; de outro, há classes subalternas que objetivam implantar o modelo democrático-popular com vistas à ampliação da proteção social (TEIXEIRA, 2013).

Essa disputa por qual projeto de sociedade deve ser implantado reflete em todos os campos, especialmente na proteção social. Nessa perspectiva, observa-se, de um lado, a preservação da concepção de seguridade social construída em diversos países da América Latina pós-Segunda Guerra Mundial como um direito social de acesso universalizado e como uma ação do Estado, tendo como defensora, notadamente, a classe trabalhadora; por outro lado, há o desmantelamento dos sistemas de proteção social com a divisão das políticas que hoje integram o sistema, para que possam ser gerenciadas e administradas pelo setor privado como objeto de consumo do capitalismo, proposta defendida pelos representantes do grande capital (MOTA, 2008).

Portanto, a falta de capacidade do capital em recuperar as suas próprias condições de lucratividade, diante do crescimento do capital fictício e de sua mundialização, resultou em uma maior competição internacional. Como consequência, visando a conservação de um cenário favorável à obtenção de lucros, exigiram-se a deterioração e a precarização das condições de trabalho, com a superexploração e a diminuição dos sistemas públicos de proteção social (MARQUES; MENDES, 2013).

Mesmo que em alguns países da América Latina os sistemas de proteção social estejam organizados de modo um pouco diverso do brasileiro, a tentativa de desmontá-los está presente e latente tanto na sociedade quanto no próprio Estado. Deve-se lutar pela reforma enquanto construção de elementos que mantenham a proteção social como um direito social universal gerido e garantido pelo Estado, e não como uma simples mercadoria do capitalismo. Para essa luta, deve-se compreender e analisar as contradições existentes no Estado capitalista periférico latino-americano na execução do desmonte dos sistemas de proteção social como requisito à visão da totalidade.

Com as contrarreformas do neoliberalismo avançando sobre os Estados latinoamericanos, sob o nome de ajustes fiscais, os gastos (investimentos) sociais são congelados (ou contingenciados) objetivando diminuir e flexibilizar orçamentos. Com 
isso, o Estado se desregulamenta e repassa suas funções de reprodução social para outras entidades (reprivatização do social), tais como: família, organizações não governamentais (ONGs), mercado e o próprio indivíduo (TEIXEIRA, 2018). Nessa perspectiva, as reformas estruturais atendem às novas exigências do capital (impostas pelas agências multilaterais) na diminuição dos gastos sociais e na ampliação de condições favoráveis à livre circulação de capital, em nome da nova ordem mundial.

Em decorrência desses movimentos, sob a perspectiva da arrecadação, consolida-se uma tendência de produção, nos países de capital dependente e periférico, onde há:

[...] políticas tributárias regressivas, mesmo em condições de baixa capacidade de tributação sobre o trabalho devido à superexploração. Assim, os recursos que poderiam ser disputados para o desenvolvimento de políticas sociais são reduzidos estruturalmente. Tal fato nos parece determinante, do ponto de vista objetivo, para compreendermos a conformação das políticas sociais dos países dependentes, que não se desenvolveram enquanto políticas universalistas, públicas e gratuitas de reponsabilidade do Estado e de direito de cidadania. (SOUZA FILHO, 2016, p. 195).

Esses fatos ficam visíveis na América Latina, já que o capital reforça a relação existente na região entre o desenvolvimento e a dependência, na qual se apresenta ao capital como unidade de ação aparentemente incontroversa. E, desse modo, a região deve, obrigatoriamente, passar por um processo de modernização que engloba a abertura internacional, a desregulamentação, a queda do nacional e a abertura das fronteiras com vistas a consolidar as políticas de zona livre, como a Área de Livre Comércio para as Américas (ALCA), os Tratados de Livre Comércio (TLCs), por projetos de reestruturação logística da Iniciativa de Integração da Infraestrutura Regional Sul-americana (IIRSA) ou pelo Mercado Comum do Sul (MERCOSUL). Junto a isso, de acordo com Tranpadini (2014), ocorrem a invisibilidade das lutas e a criminalização dos sujeitos e movimentos que tentam atuar e pensar em outro ponto que não aquele dentro da ordem e da lógica neoliberal.

Nesse cenário, Couto (2015) realiza alguns questionamentos relevantes: teria sentido debater e construir ciência sobre o campo da proteção social em tempos de capitalismo financeiro e de neoliberalismo? A estrutura até então criada pós-Segunda Guerra Mundial na concertação entre capital versus trabalho foi desmanchada? Em tempos de barbárie já não seria a hora da academia e dos profissionais reconhecerem a funcionalidade unilateral das políticas sociais para o capital, tantas vezes já anunciadas?

Para tais questionamentos não há uma única resposta, sendo que todas ensejam um refletir crítico acerca da realidade e da possibilidade de mudança para o futuro. Contudo, uma coisa é certa: todas essas contrarreformas estão a serviço dos ajustes estruturais impostos pelo capital ao mesmo tempo em que, contraditoriamente, assiste-se a pessoas vagando pelo mundo, pelos Estados e pelas cidades sendo obstaculizadas por construção de muros em números cada vez maiores (COUTO, 2015).

Na sociedade contemporânea (talvez não tão contemporânea assim), a lógica perversa do capital fetiche na América Latina acaba por resumir os sistemas de proteção social à sua assistência, à boa vontade privada e à benemerência, embutindo na classe trabalhadora os custos da destruição que o capital financeiro vem articulando na 
população mundial. Nesse sentido, coaduna-se com Couto (2015): “[...] o custo disso é 'insustentável'! A retração passa a ser anunciada como a única salvação do capital, que é propagado como essencial à vida humana e, portanto, deve ser preservada, inclusive à custa da própria vida!" (COUTO, 2015, p. 23).

\section{Considerações finais}

No que diz respeito aos sistemas de proteção social, a América Latina tem sido palco de tensionamentos sociais e uma arena de correlações de forças que promovem momentos de reformas (com garantia de direitos) e momentos de contrarreformas (com retirada de direitos). Esses movimentos refletem o caráter pendular que a garantia de direitos assume na contemporaneidade, já que ora o pêndulo se move para a esquerda e ora esse mesmo pêndulo se desloca para a direita. Por isso, tal fenômeno demanda uma percepção da realidade para que seja possível verificar sua totalidade.

No momento em que o pêndulo se desloca para o extremo da proteção, ocorre a diminuição dos índices de pobreza e de desigualdades, contudo, quando alcança o seu inverso, provoca sérias violações de direitos. Particularmente, a pobreza e a exclusão social, mesmo sendo elementos de formação histórica, sofreram um considerável aprofundamento no continente latino-americano a partir das crises econômicas que assolaram grande parte das nações situadas na região nos anos de 1980, quando os problemas sociais, até então estruturados no local, se modificaram em obstáculos reais e inimagináveis para a construção de sociedades mais justas, igualitárias e democráticas.

Com base nesse contexto, o estudo pretendeu compreender os principais elementos (políticos, econômicos e sociais) semelhantes presentes nos processos de reformas e de contrarreformas dos sistemas de proteção social na América Latina. Com esse objetivo, questionou-se: quais são os principais elementos semelhantes presentes nos processos de reforma e/ou contrarreforma nos sistemas de proteção social na América Latina?

O caminho percorrido pelo estudo da dualidade contraditória da proteção social possibilita à sociedade capitalista de orientação neoliberal refletir sobre o campo de antítese dos princípios de acumulação. A luta pelo reconhecimento de direitos da população latino-americana, no âmbito dos sistemas de proteção social, implica marcas significativas de aproximação do Serviço Social, do Direito e das demais áreas do conhecimento na possibilidade de pensar uma nova direção ao Estado e às políticas sociais.

Sob esse novo pensar transdisciplinar e a partir da realidade é que as contradições dos sistemas de proteção social no Estado capitalista periférico na América Latina se fundamentam quando, por meio dessa conjectura, surge a necessidade de construção de um processo dialógico com as desigualdades sociais, a extrema pobreza e os sistemas de proteção social. Tal interação constituiu um desafio na América Latina, sobretudo na atual fase das sociedades em que o conservadorismo voltou a ditar as regras, sob o comando do neoliberalismo. Quando se fala em realidade latino-americana e na necessidade de compreender os fenômenos aqui produzidos e reproduzidos, fala-se em uma região que tem um gasto público mediano menor que $15 \%$ do PIB e, ao mesmo

Argum., Vitória, v. 12, n. 2, p. 284-298, maio/ago. 2020. | ISSN 2176-9575 
tempo, com as taxas de pobreza e de indigência elevadas: $28,2 \%$ e $11,3 \%$, respectivamente (COMISSÃO ECONÔMICA PARA A AMÉRICA LATINA E O CARIBE, 2019).

Mesmo diante desse cenário lastimável, a pesquisa demonstrou que as contrarreformas concretizadas por ditames neoliberais nos sistemas de proteção social avançam sobre os Estados latino-americanos e, em nome de ajustes fiscais, os gastos (investimentos) sociais são congelados (ou contingenciados), objetivando diminuir e flexibilizar orçamentos. Com isso, o Estado se desregulamenta e repassa suas funções de reprodução social para outras entidades (reprivatização do social).

Nessa perspectiva, mesmo que haja pequenas diferenças na atuação do neoliberalismo nos mais diversos Estados da América Latina, a semelhança nas contrarreformas estruturais é unânime: observa-se a necessidade comum de atender às novas exigências do capital, com o apoio de agências multilaterais na diminuição dos gastos sociais para possibilitar novas condições para a livre circulação do capital e o aumento de seus lucros.

\section{Referências}

AMARAL, A. S. Precarização estrutural e exploração da força de trabalho: tendências contemporâneas. Argumentum, Vitória, v. 10, n. 3, p. 244-256, 2018.

DOI: https://doi.org/10.18315/argumentum.v10i3.19549. Disponível em:

https://periodicos.ufes.br/index.php/argumentum/article/view/19549. Acesso em: 22 jun. 2019.

BEHRING, E. R. Brasil em contrarreforma: desestruturação do Estado e perda de direitos. 2. ed. São Paulo: Cortez, 2008.

BEHRING, E. R.; BOSCHETTI, I. Política Social: fundamentos e história. 9. ed. São Paulo: Cortez, 2011.

BENTURA, J. P. Los Programas de Transferencia de Renta Condicionadas como gestión neoliberal de la cuestión social. Revista Serviço Social e Sociedade, São Paulo, n. 117, p. 94-121, 2014 .

BOSCHETTI, I. Seguridade social na América Latina. In: BOSCHETTI, I. et al. (Org.). Política social no capitalismo: tendências contemporâneas. 2. ed. São Paulo: Cortez, 2009. p. 174-195.

CARLOTO, C. M.; NOGUEIRA, B. W. F. Família, gênero e proteção social. Em Pauta, Rio de Janeiro, v. 16, n. 42, p. 49-64, 2018.

COMISSÃO ECONÔMICA PARA A AMÉRICA LATINA E O CARIBE. Panorama social de América Latina 2018. Santiago do Chile: CEPAL, 2019.

COUTO, B. R. Proteção social em tempos de capitalismo financeiro. Revista Argumentum, Vitória, v. 7, n. 2, p. 22-23, 2015. 
DOI: https://doi.org/10.18315/argumentum.v7i2.11400. Disponível em:

https://periodicos.ufes.br/argumentum/article/view/1140o. Acesso em: 22 jun. 2019.

COUTO, B. R.; RIZZOTTI, M. L. Estado brasileiro, direitos constitucionais e os desafios da proteção social no Século XXI. In: CONSERVA, M. S. (Org.).

Multiterritorialidades e os desafios da proteção social no Brasil e na Europa. João Pessoa: CCTA, 2016. p. 107-124.

LOURENÇO, E. A. S.; LACAZ, F. A. C.; GOULART, P. M. Crise do capital e desmonte da Previdência Social no Brasil. Revista Serviço Social e Sociedade, São Paulo, n. 130, p. 467-486, 2017.

MARQUES, R. M.; MENDES, A. A proteção social no capitalismo contemporâneo em crise. Argumentum, Vitória, v. 5, n. 1, p. 135-163, 2013.

DOI: https://doi.org/10.18315/argumentum.v5i1.5173. Disponível em:

https://periodicos.ufes.br/argumentum/article/view/5173. Acesso em: 22 jun. 2019.

MATTEI, L. Políticas sociais de enfrentamento da pobreza na América Latina: uma análise comparada entre Brasil e Argentina. Revista Katálysis, Florianópolis, v. 18, n.

2, p. 222-230, 2013.

MOTA, A. E. S. Cultura da crise e seguridade social: um estudo sobre as tendências da previdência e da assistência social brasileiras nos anos 80 e 90. 5. ed. São Paulo:

Cortez, 2008.

NETTO, J. P. Capitalismo monopolista e serviço social. São Paulo: Cortez, 1992.

OXFAM BRASIL. Recompensem o trabalho e não a riqueza. Oxfam Brasil, [s. l.], 2018. Disponível em: https://www.oxfam.org.br/. Acesso em: 3 abr. 2019.

PEREIRA, C. P. Proteção social no capitalismo: crítica a teorias e ideologias conflitantes. São Paulo: Cortez, 2016.

PEREIRA, P. A. P. Política social: temas \& questões. 2. ed. São Paulo: Cortez, 2009.

PEREIRA, P. A. P. Questão social, Serviço Social e direitos de cidadania. Revista Temporalis, Brasília, n. 3, p. 51-62, 2001.

RAICHELIS, R. Gestão pública e a questão social na grande cidade. Revista Lua Nova, São Paulo, v. 69, p. 13-48, 2006.

SANTOS, M. S. As influências das agências multilaterais nas "reformas" da previdência social brasileira. Revista Ser Social, Brasília, v. 19, n. 40, p. 13-30, 2017.

SENNA, M. C. M.; MONNERAT, G. L. O setor saúde e os desafios à construção da seguridade social brasileira. In: BEHRING, E. R.; ALMEIDA, M. H. T. (Org.). Trabalho e seguridade social: percursos e dilemas. 2. ed. São Paulo: Cortez, 2010, p. 193-213. 
SILVA, M. L. L. Contrarreforma da Previdência Social sob o comando o capital financeiro. Revista Serviço Social e Sociedade, São Paulo, n. 131, p. 130-154, 2018. SILVA, M. S.; SCHMIDT, J. A. Seguridade social em um contexto de dívida pública na América Latina. Revista Ser Social, Brasília, v. 18, n. 39, p. 329-348, 2016.

SOUZA, C. L. S. Capitalismo dependente e políticas sociais na América Latina. Argumentum, Vitória, v. 8, n. 1, p. 48-6o, 2016.

DOI: https://doi.org/10.18315/argumentum.v8i1.11827.Disponível em: https:/periodicos.ufes.br/index.php/argumentum/article/view/11827. Acesso em: 22 jun. 2019.

SOUZA FILHO, R. Fundo público e políticas sociais nos Estados dependentes: considerações teóricas. Revista em Pauta, Rio de Janeiro, v. 14, n. 37, p. 174-198, 2016.

TEIXEIRA, A. P. Política de previdência social. In: REZENDE, I.; CAVALCANTI, L. F. (Org.). Serviço social e políticas sociais. 4. ed. Rio de Janeiro: UFRJ, 2013. p. 47-66.

TEIXEIRA, S. M. O envelhecimento e as reformas no Sistema de Seguridade Social no Brasil contemporâneo. Revista Textos \& Contextos, Porto Alegre, v. 17, n. 1, p. 126137, 2018.

TRANPADINI, R. Dependência e luta de classes na América Latina. Revista Argumentum, Vitória, v. 6, n. 2, p. 29-43, 2014. DOI: 10.18315/argumentum.v6i2.8504. Disponível em: https://periodicos.ufes.br/index.php/argumentum/article/view/8504. Acesso em: 22 jun. 2019.

VALLE, K. F. Estado e crise do capital: debatendo as perdas da proteção social. Revista Argumentum, Vitória, v. 5, n. 1, p. 85-101, 2013.

DOI: https://doi.org/10.18315/argumentum.v5i1.4840. Disponível em: https://periodicos.ufes.br/argumentum/article/view/4840. Acesso em: 22 jun. 2019.

Rodrigo Cristiano Diehl Trabalhou na redação do artigo e revisão crítica.

Doutorando em Direito pelo Programa de Pós-Graduação em Direito da UNISC com coorientação pelo Programa de Pós-Graduação em Ciência Política da UFRGS, com bolsa CAPES. Mestre em Política Social e Serviço Social pela UFRGS. Mestre em Direito pela UNISC, com bolsa CAPES.

Jussara Maria Rosa Mendes Trabalhou na redação do artigo e revisão crítica.

Doutora em Serviço Social pela PUC/SP, com pós-doutorado em Serviço Social pela Universität Kassel. Professora colaboradora do Programa de Pós-Graduação em Política Social e Serviço Social e do Programa de Pós-Graduação em Psicologia Social e Institucional, ambos da UFRGS. Representante de área junto ao CNPq. 